\title{
Legalizing and Regulating Marijuana in Canada: Review of Potential Economic, Social, and Health Impacts
}

\begin{abstract}
Mohammad Hajizadeh*
Abstract

Notwithstanding a century of prohibition, marijuana is the most widely used illicit substance in Canada. Due to the growing public acceptance of recreational marijuana use and ineffectiveness of the existing control system in Canada, the issue surrounding legalizing this illicit drug has received considerable public and political attentions in recent years. Consequently, the newly elected Liberal Government has formally announced that Canada will introduce legislation in the spring of 2017 to start legalizing and regulating marijuana. This editorial aims to provide a brief overview on potential economic, social, and public health impacts of legal marijuana in Canada. The legalization could increase tax revenue through the taxation levied on marijuana products and could also allow the Government to save citizens' tax dollars currently being spent on prohibition enforcement. Moreover, legalization could also remove the criminal element from marijuana market and reduce the size of Canada's black market and its consequences for the society. Nevertheless, it may also lead to some public health problems, including increasing in the uptake of the drug, accidents and injuries. The legalization should be accompanied with comprehensive strategies to keep the drug out of the hands of minors while increasing awareness and knowledge on harmful effects of the drug. In order to get better insights on how to develop an appropriate framework to legalize marijuana, Canada should closely watch the development in the neighboring country, the United States, where some of its states viz, Colorado, Oregon, Washington, and Alaska have already legalized recreational use of marijuana.

Keywords: Legalization of Marijuana, Economic Effect, Social Effects, Health Effects, Canada

Copyright: ( 2016 by Kerman University of Medical Sciences

Citation: Hajizadeh M. Legalizing and regulating marijuana in Canada: review of potential economic, social, and health impacts. Int J Health Policy Manag. 2016;5(8):453-456. doi:10.15171/ijhpm.2016.63
\end{abstract}

Article History:

Received: 25 April 2016 Accepted: 21 May 2016 ePublished: 25 May 2016

\section{(2)}

*Correspondence to:
Mohammad Hajizadeh
Email: m.hajizadeh@dal.ca

\section{Background}

Marijuana (commonly known by the street names "pot," "weed," and "grass") comes from the plant Cannabis sativa (hemp). It is one of the oldest naturally psychoactive substances known to humans and grows naturally in many countries. $^{1,2}$ Although marijuana has been used for both medicinally and recreationally throughout the world for thousands of years, ${ }^{1}$ it still remains illegal to grow, use and possess in most countries, including Canada, ${ }^{3}$ which has been illegal since 1923. Although it is illegal to use marijuana for recreational purposes, its use as a potential therapy is legal and deemed appropriate by the Supreme Court of Canada since July 30, 2001.

Despite almost a century of prohibition, with $43 \%$ of Canadians claiming to have used at some point in their life, marijuana is the most widely used illicit substance in Canada. ${ }^{4}$ The prevalence of marijuana use varies by province, gender, and age groups in Canada. According to the data from the 2012 Canadian Community Health Survey-Mental Health (CCHS$\mathrm{MH}$ ), while more than $14 \%$ of Canadian (aged 15 and older) living in Nova Scotia and British Columbia reported that they have inhaled at least once in the past year, this figure was almost $10 \%$ in the Prince Edward Island and Saskatchewan. Canadian youth has the highest rate of marijuana use among developed countries, with almost a quarter of the population aged 15 to 24 years reporting past-year use. ${ }^{5}$ Males are also more likely to have reported past-year use than their females counterparts in all age groups. ${ }^{4}$

Due to the ineffectiveness of the current system of prohibition in Canada, the issue surrounding legalizing and decriminalizing marijuana has attracted significant political and media attentions in recent years. Decriminalization of marijuana would mean that the personal use of the substance is still illegal and can lead to a small legal fine, but no longer classified as a criminal offense. Legalization of marijuana, on the other hand, means that marijuana would belegally available to adults. ${ }^{6}$ Legalization, which allows governments to regulate the use and sale of marijuana like tobacco and alcohol, has been a very controversial issue due to various moral, ethical, public health, legislative and logistic issues associated with the matter. The proponents of the legalization, for example, argue that the use of marijuana is much less associated with income generating crime because it is insignificant component of household budgets and has lower danger in terms of possibility of overdose, risk of tragic intoxicated behavior and risk of addiction. ${ }^{7}$ Those opposed to legalization cite concerns such as increased use $\mathrm{e}^{8,9}$ and potential abuse and easing the manner by which minors manage to purchase and use the drug. ${ }^{10,11}$ The results from public opinion polls conducted over the past two decades have revealed that an increasing majority of Canadians agree with the decriminalization or legalization of marijuana. ${ }^{12-16}$ For example, a recent poll conducted in 2015 by the Forum Research suggested that $68 \%$ of Canadians favor relaxing marijuana regulations in Canada. ${ }^{17}$ The public support for legalization has been slowly garnering media attention, putting pressure on the legislatures and the Government to amend the outdated laws surrounding the drugs use. The issue of legalizing marijuana have been featured by multiple 
news agencies since $2015\left(\mathrm{eg},{ }^{18,19}\right)$. With considerable public and media support, it came as no surprise to see a large part of the Liberals' election campaign was centered on the issue of the legalizing marijuana. Subsequently, the newly elected Prime Minister Justin Trudeau has publically endorsed the legalization of the recreational use of marijuana in November 2015 and is currently working on the legal framework to introduce legislation in the spring of 2017 to start the process of regulating and legalizing marijuana. ${ }^{20} \mathrm{~A}$ federal bill to legalize marijuana would make Canada the first developed country to legalize marijuana in the world.

There is still a lot of work to be done if Canada aims to pursue the Liberal goal of legalization of Marijuana. There are three international conventions that Canada is a part of that and need to be changed in order for any progress to be made: the Convention of Psychotropic Substances of 1971; the Single Convention on Narcotic Drugs of 1961, as amended by the 1972 Protocol; and the United Nations Convention against Illicit Traffic in Narcotic Drugs and Psychotropic Substances of 1988. All these international conventions require its participant countries to criminalize the production and possession of marijuana. Although it may not be necessary for Canada to completely withdraw from all these conventions, Canada should indicate that legalizing recreational marijuana will reduce the consumption of the illicit drug. ${ }^{21}$ Thus, not only is it evident that massive reform is required in terms of issues surrounding the legalization in Canada, but also ensuring that the reform is implemented with the utmost consideration and care remains critical. This editorial briefly reviews some of the potential economic, social and health outcomes of legal marijuana in Canada.

\section{Economic Impacts}

The most appealing argument in favor of legalization of marijuana is the increased tax revenue that it would bring to the Canadian economy. Legalizing marijuana provides an important advantage over prohibition because it allows for the Government to collect taxes from the legalized drug. Specifically, high demand for recreational marijuana in Canada indicates that legalization of the drug would yield significant tax revenue. The free market price of marijuana is estimated to be particularly low without taxation. This allows for the Government to impose higher taxes on marijuana while keeping the price at a competitive level with other intoxicants (eg, alcohol and tobacco). ${ }^{22}$

The taxation revenue of legalized marijuana products has already been proven in Colorado, in the United States, where marijuana is legalized since January 1, 2014. Colorado has gained international interest as one of the first states in the United States to allow for legal buying and selling of marijuana. The results from Colorado's first two years of legalization show significant monetary tax revenue. With recreational and medicinal sales reaching almost $\$ 1$ billion in 2015, Colorado collected more than $\$ 135$ million in taxation revenue and fees. ${ }^{23,24}$ To ensure that positive outcomes occur alongside the considerable economic boost, the generated tax revenue is used for the state's public school capital construction assistance fund, and public programs such as substance abuse and regulation of marijuana use. ${ }^{23}$ This is to ensure that any adverse effects caused by the legalization were paid for by its own generated tax revenue.

The legalization of recreational marijuana in Canada could generate substantial taxation revenue due to the presence of significant black market for marijuana as the second most consumed substance nationwide, behind only that of alcohol. ${ }^{25}$ Based on the results of a new report by the Canadian Imperial Bank of Commerce (CIBC) World Markets, ${ }^{26}$ the legalization of marijuana could create a $\$ 10$ billion a year industry and the Canadian government can collect $50 \%$ or more of the potential $\$ 10$ billion if there is a high "sin tax" (ie, taxes levied on goods such as alcohol and tobacco products that regarded harmful to society) set on marijuana products. The legalization could result in the employment of more workers who can grow and package marijuana for sale in the Government approved grow-ops. It also could generate some other job opportunities for individuals who can work in educational sessions and health promotion initiatives to promote safe use of the drug. Nevertheless, due to automation and economies of scale, legalization would probably reduce the overall employment in Canada because the number of legal jobs generated (eg, growers, distributors, and accountants) would probably be smaller compared to the number of illegal jobs eliminated. Furthermore, legalization of marijuana in Canada could substantially reduce the Government's spending on the enforcement of the federal marijuana laws. According to a report by Statistics Canada, there were 73000 marijuanarelated criminal offences ( $67 \%$ of all police-reported drug offences) in 2013. This number has, in fact, increased approximately $8 \%$ over the period of 10 years from 2003 to 2013. ${ }^{27}$ The current marijuana policy and legal framework is associated with considerable government costs of approximately $\$ 500$ million $^{28}$ to $\$ 1$ billion $^{29}$ per annum. Legalization of marijuana could lead to substantial savings in drug incarceration and enforcement costs in Canada.

\section{Social Impacts}

The high demand for marijuana in Canada has resulted in the expansion of the black market and puts the power in the hands of illegal drug dealers to be the sole providers of the product with no accountability. By taking control of the distribution of marijuana, legalization could reduce the flourishing black market for the drug, which is the cause for a large amount of illegal activity in Canada as indicated by the rate of police-reported marijuana offences. ${ }^{27}$ Legalization can address some of the social problems associated with the black market for marijuana such as unsafe environments created by the illegal distribution of the drug and the negative consequences of criminal labeling for possession of small amounts of marijuana.

The illegal market for marijuana is a major risk to the wellbeing of Canadian children. A recent report by the United Nations Children's Fund (UNICEF Office of Research, 2013) placed Canadian teens and children as the highest users of illegal marijuana among 29 of the world's developed economies. With $28 \%$ of Canadian youth (aged 11-15) having used marijuana illegally in the past year, ${ }^{30}$ legalization could potentially minimize the children's direct contact with black market activity. Removing this illegal access point through the legalization could be beneficial in terms of reducing youth illegal activity rates, and diminishing the drug dealers' power 
over Canadian youth. It should be mentioned that while legalization will reduce the size of the black market activity, it will not eliminate the issue altogether. ${ }^{31}$

\section{Public Health Impacts}

Although there is some evidence indicating therapeutic benefits of marijuana use in neuropathic pain, inflammatory bowel diseases, managing symptoms of chemotherapy and treatment-resistant epilepsy in children, marijuana use is associated with adverse health effects. ${ }^{32-35}$ According to a recent report by the Centre for Addiction and Mental Health (CAMH), the regular usage of marijuana is associated with some health risk such as: problems with healthy brain development among youth, progression to use of other illicit drugs, depression or anxiety injury and risk of death from motor vehicle collisions, symptoms of chronic bronchitis, schizophrenia and addiction problem..$^{29,36,37}$ Based on causal effects on marijuana use disorders, schizophrenia, lung cancer and road traffic injuries, Imtiaz and colleagues ${ }^{38}$ showed that marijuana use caused 287 deaths and 66346 disabilityadjusted life years (DALYs) in 2012. While marijuana-related mortality was estimated to occur due to the causal effects of marijuana use on motor-vehicle accidents and lung cancer, the number of morbidity cases attributable to marijuana use was by far the highest in motor-vehicle accidents and use disorders domains in Canada. ${ }^{39}$

Similar to Colorado's experience with legal marijuana, ${ }^{40}$ legalization in Canada could lead to an increase in the recreational use of the drug among adults which, in turn, could result in the health risks associated with the substance use. Increased in marijuana-related traffic deaths ${ }^{41}$ and utilization of healthcare has been documented in Colorado after the availability of the legal marijuana. There have been also increases in the marijuana-related healthcare utilization due to intoxication, burns and cyclic vomiting syndrome and eating edible marijuana among children in Colorado. ${ }^{42}$ Given the adverse health outcomes associated with legal marijuana in Canada, ${ }^{29}$ strategies on marijuana control should focus on prevention and harm reduction programs, as recommended by the CAMH. Specifically, a comprehensive framework should be developed to prevent the impaired driving, provide better access to treatment and increase awareness about the drug and its effects in Canada.

\section{Concluding Remarks}

Legalization of marijuana not only has the potential to generate tax revenue from the subsequent taxation that will occur, but it will also allow the government to save citizens' tax dollars currently being spent on prohibition legislation. The profits and saved tax dollars could be spent on public education and health promotion programs. Additionally, legalization will remove the criminal element from marijuana market and reduce the size of Canada's black market and its consequences for the society. However, legal marijuana can also lead to some public health problems, including increasing in the use of the drug, accidents and injuries. Legalization could be only effective if the Canadian government develops appropriate strategies to keep the drug out of the hands of minors, to increase awareness and knowledge on harmful effects of the drug and to prevent impaired driving.
Canada is not the first country that attempts to end prohibition of marijuana. Countries such as the Netherlands, Portugal, Uruguay, and the United States have experienced a change in their marijuana prohibition policies and can provide useful lessons and models for Canada. More specifically, Canada should follow the developments of changes in marijuanarelated regulations in the United States, where some of its states viz, Colorado, Oregon, Washington, and Alaska have already legalized recreational use of marijuana. Although experience of legalization in these states is different from the national legalization in Canada, these examples still can provide valuable information during the drafting of the new law in Canada. Moreover, legalization of marijuana in Canada will offer a unique opportunity to study the effect of legalizing marijuana on the national scale.

\section{Acknowledgments}

The author would like to thank three anonymous reviewers for their helpful comments and suggestions. I also thank Michael Lebenbaum for his proof-reading of the final draft of this paper.

Ethical issues

Not applicable.

\section{Competing interests}

Author declares that he has no competing interests.

Author's contribution

$\mathrm{MH}$ is the single author of the paper.

\section{References}

1. Ben Amar M. Cannabinoids in medicine: A review of their therapeutic potential. J Ethnopharmacol. 2006;105(1-2):1-25. doi:10.1016/j.jep.2006.02.001

2. Cayer A. The "High" Economic Benefits of Legalizing Marijuana in Canada. http://www.ruor.uottawa.ca/ bitstream/10393/25386/1/2010_cayer_aaron.pdf. Published 2010.

3. Adler JN, Colbert JA. Medicinal Use of Marijuana - Polling Results. N Engl J Med. 2013;368(22):e30. doi:10.1056/ nejmclde1305159

4. Rotermann M, Langlois K. Prevalence and correlates of marijuana use in Canada, 2012. Health Rep. 2015;26(4):10-15.

5. George T, Vaccarino F. Substance Abuse in Canada. Ottawa, ON; 2015.

6. Morse T. Decriminalization Versus Legalization of Marijuana. http://uspolitics.about.com/od/warondrugs/fl/DecriminalizationVersus-Legalization-of-Marijuana.htm. Published 2016.

7. Caulkins JP, Kasunic A, Kleiman M, Lee MAC. Understanding drug legalization. Int Public Health J. 2014;6(3):283-294.

8. Svrakic DM, Lustman PJ, Mallya A, Lynn TA, Finney R, Svrakic NM. Legalization, decriminalization \& medicinal use of cannabis: a scientific and public health perspective. Mo Med. 2012;109(2):90-99.

9. Joffe A, Yancy WS. Legalization of marijuana: potential impact on youth. Pediatrics. 2004;113(6):e632-e638. doi:10.1542/ peds.113.6.e632

10. Salomonsen-Sautel S, Sakai JT, Thurstone C, Corley R, Hopfer C. Medical marijuana use among adolescents in substance abuse treatment. J Am Acad Child Adolesc Psychiatry. 2012;51(7):694702. doi:10.1016/j.jaac.2012.04.004

11. Thurstone C, Lieberman SA, Schmiege SJ. Medical marijuana 
diversion and associated problems in adolescent substance treatment. Drug Alcohol Depend. 2011;118(2-3):489-492. doi:10.1016/j.drugalcdep.2011.03.031

12. COMPAS Inc. Canada: Two-Thirds Favour Decriminalizing Pot. Toronto, Ontario; 2000.

13. Savas D. Public Opinion and Illicit Drugs Canadian Attitudes towards Decriminalizing the Use of Marijuana. Vancouver, BC; 2001.

14. SES Research. Perceptions on Marijuana Decriminalization. Toronto, Ontario; 2005. http://www.sesresearch.com/news/ press_releases/PR February 28 2005.pdf.

15. Angus Reid. Half of Canadians Support the Legalization of Marijuana. Vancouver, BC; 2010. http://angusreidglobal.com/ wp-content/uploads/2010/11/2010.11.29_Drugs_CAN.pdf.

16. Forum Research Inc. More than Two Thirds Support Decriminalization/legalization of Marijuana. Toronto, Ontario; 2013. http://www.forumresearch.com/forms/News Archives/ News Releases/50140_Federal_Trudeau_-_Marijuana_ (24082013)_Forum_Research.pdf.

17. Froum Research Inc. Support for Marijuana Legalization Steady at More than Half. Toronto, Ontario; 2015. http://poll. forumresearch.com/post/1362/just-one-tenth-think-currentlaws-are-appropriate.

18. Evans P. $20 \%$ of Canadians smoked pot last year, but more than $30 \%$ would if legal, poll suggests. CBC News. November 10, 2015. http://www.cbc.ca/news/business/marijuana-pot-pollsurvey-1.3312151.

19. Armstrong J. Majority of Canadians support decriminalizing marijuana: poll. Global News. August 19, 2015. http:// globalnews.ca/news/2173919/majority-of-canadians-supportdecriminalizing-marijuana-poll/.

20. Smith J. Marijuana legislation coming to Canada next spring. The Star. April 20, 2016. http://www.thestar.com/news/ canada/2016/04/20/marijuana-legislation-coming-to-canadanext-spring.html.

21. Blanchfield M. Legalizing pot in Canada wil run afoul of global treaties, Trudeau warned. CBC News. January 5, 2016. http:// www.cbc.ca/news/politics/trudeau-legalizing-pot-globaltreaties-1.3390745.

22. Glauser D. The economic effects of legalizing marijuana. http://content.lib.utah.edu/utils/getfile/collection/etd3/id/1880/ filename/1882.pdf. Published 2012.

23. Government of Colorado. Colorado Marijuana Tax Data. https:// www.colorado.gov/pacific/revenue/colorado-marijuana-tax-data. Accessed April 20, 2016. Published 2016.

24. Government of Colorado. Marijuana Taxes, Licenses, and Fees Transfers and Distribution. https://www.colorado.gov/pacific/ sites/default/files/1215 Marijuana Tax\%2C License $\% 2 \mathrm{C}$ and Fees Report.pdf. Published 2015.

25. Canadian Center on Substance Abuse. Cannabis. Ottawa, Canada; 2016. http://www.ccsa.ca/Resource\%20Library/CCSA-
Canadian-Drug-Summary-Cannabis-2016-en.pdf.

26. Shenfeld A. Economic Insights: The Winter of Our Discontent. Toronto, Ontario; 2016. http://research.cibcwm.com/economic_ public/download/eijan16.pdf.

27. Cotter A, Greenland J, Karam M. Drug-Related Offences in Canada, 2013. Ottawa, Canada; 2015.

28. Nolin PC, Kenny C. Cannabis: Our Position for a Canadian Public Policy. Ottawa, ON; 2002.

29. Crépault J. Cannabis Policy Framework-CAMH. Toronto, Canada; 2014. http://www.camh.ca/en/hospital/about_camh/influencing_ public_policy/documents/camhcannabispolicyframework.pdf.

30. UNICEF Office of Research. Child Well-Being in Rich Countries: A Comparative Overview. Florence, Italy; 2013.

31. Ruschmann P. Legalizing Marijuana. New York, USA: Infobase Publishing; 2009.

32. Bronskill J. Legalizing marijuana: Health Canada flags 9 factors for Liberals to consider. The Canadian Press. March 5, 2016.

33. Esposito G, De Filippis D, Cirillo C, et al. Cannabidiol in inflammatory bowel diseases: a brief overview. Phyther Res. 2013;27(5):633-636. doi:10.1002/ptr.4781

34. Moore TH, Zammit S, Lingford-Hughes A, et al. Cannabis use and risk of psychotic or affective mental health outcomes: a systematic review. Lancet. 2007;370(9584):319-328. doi:10.1016/s0140-6736(07)61162-3

35. Meier MH, Caspi A, Ambler A, et al. Persistent cannabis users show neuropsychological decline from childhood to midlife. Proc Natl Acad Sci. 2012;109(40):E2657-E2664. doi:10.1073/ pnas.1206820109

36. Volkow ND, Baler RD, Compton WM, Weiss SR. Adverse health effects of marijuana use. N Engl J Med. 2014;370:2219-2227.

37. World Health Organization (WHO). Management of substance abuse: Cannabis. http://www.who.int/substance_abuse/facts/ cannabis/en/. Accessed May 5, 2016. Published 2016.

38. Imtiaz S, Shield KD, Roerecke M, et al. The burden of disease attributable to cannabis use in Canada in 2012. Addiction. 2016;111(4):653-662.

39. Fischer B, Imtiaz S, Rudzinski K, Rehm J. Crude estimates of cannabis-attributable mortality and morbidity in Canadaimplications for public health focused intervention priorities. $J$ Public Health (Oxf). 2016; 38(1):183-188. doi:10.1093/pubmed/ fdv005

40. Center for Disease Control and Prevention. Behavioral Risk Factor Surveillance System (BRFSS) Survey. USA: CDC; 2014.

41. Rocky Mountains HIDTA. Legalization of Marijuana in Colorado: The Impact. http://www.rmhidta.org/html/august $\% 202014 \% 20$ legalization\%20of\%20mj\%20in\%20colorado\%20the\%20impact. pdf. Published 2015

42. Monte AA, Zane RD, Heard KJ. The implications of marijuana legalization in colorado. JAMA. 2015;313(3):241-242. doi:10.1001/jama.2014.17057 